Supplement of Eur. J. Mineral., 32, 405-425, 2020

https://doi.org/10.5194/ejm-32-405-2020-supplement

(C) Author(s) 2020. This work is distributed under

the Creative Commons Attribution 4.0 License.

(c) (1)

Supplement of

\title{
Partial melting of zoisite eclogite from the Sanddal area, North-East Green- land Caledonides
}

Wentao Cao et al.

Correspondence to: Wentao Cao (cao@fredonia.edu)

The copyright of individual parts of the supplement might differ from the CC BY 4.0 License. 


\section{Supplement SI}

This supplement includes a set of pseudosections along with compositional isopleths and mineral isomodes modeled for the zoisite eclogite 03-57. 
Figures


Figure S1. $P-T$ pseudosection modeled with an XRF-derived bulk composition of sample 03-57.

See text for detailed modeling parameters. a) Calculated $P-T$ pseudosection along with mineral assemblages and highlighted phase boundaries of kyanite, zoisite, melt (L). Abbreviations are described in Table 1; V = fluid. Dashed line of Nacpx indicates Na content in M2 site in clinopyroxene; the line separates the mineral assemblages with calcic pyroxene (diopside, NaCpx 
$<0.20$ ) from those with sodic-calcic pyroxene (omphacite, $\mathrm{NaCpx}>0.20$ ). b) compositional isopleths of $\mathrm{Si}$-in-Ph and $\mathrm{X}_{\mathrm{Na}}-\mathrm{in}-\mathrm{Cpx}$ within the modeled $P$-T space. The purple area marks where the highest values of $\mathrm{Si}-\mathrm{in}-\mathrm{Ph}$ and $\mathrm{XNa-in}-\mathrm{Cpx}$ intersect. Cpx refers to omphacite at this pressure. Note that this intersection is not used to determine the true peak pressure, but to estimate a peak $P$ to determine a $P$-T path across which an initial melt, that is reintegrated into bulk composition for a melt-reintegrated pseudosection, is generated. c) isomodes of garnet and melt. d) isomodes of clinopyroxene, kyanite and zoisite. 

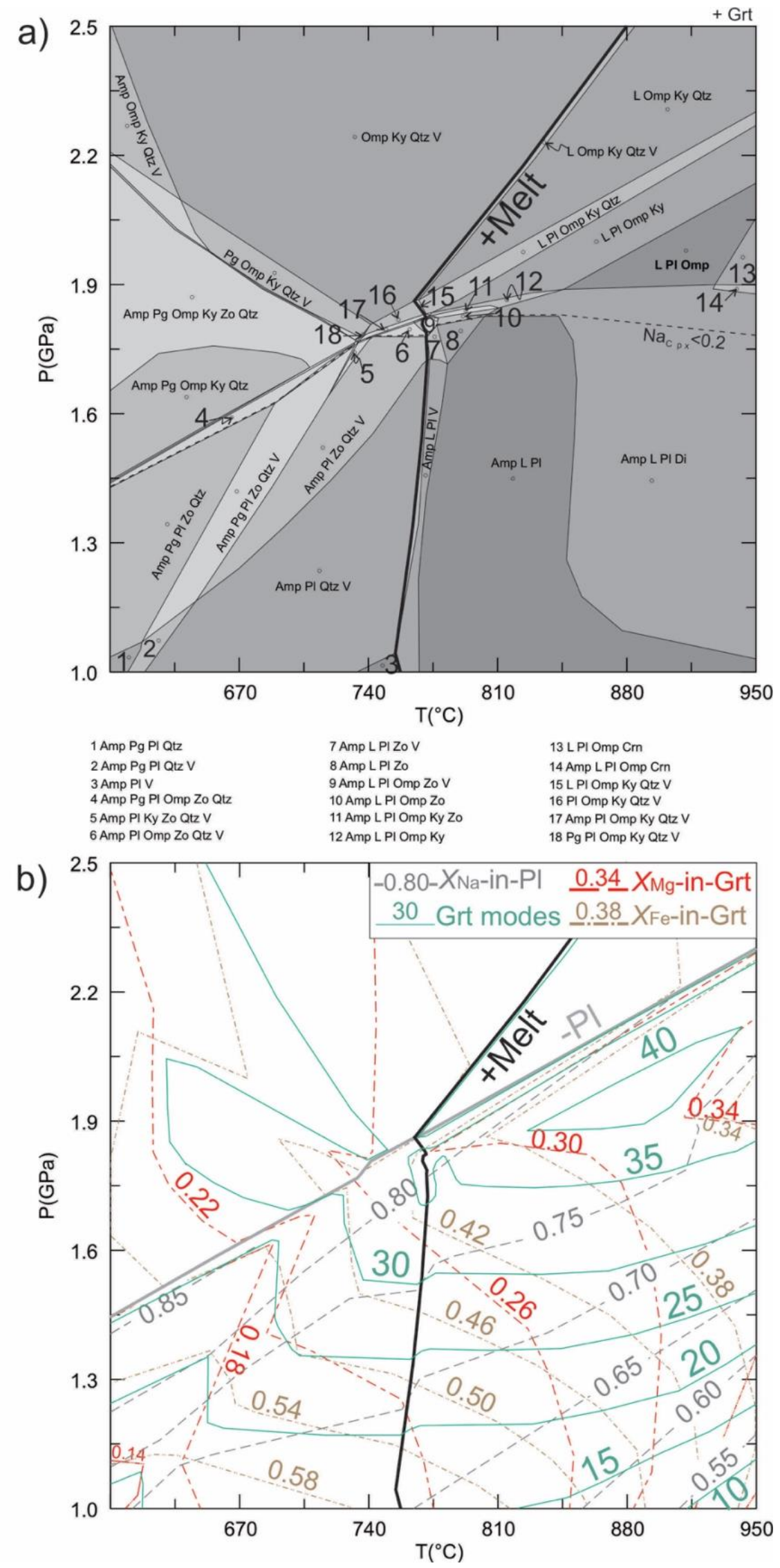
Figure S2. $P-T$ pseudosection modeled for a melt domain in zoisite eclogite 03-57. See text for detailed modeling parameters. a) calculated $P-T$ pseudosection of the melt domain, with the solidus curve highlighted. The field with observed mineral assemblage of garnet, plagioclase, omphacite and melt are shown with bold fonts at 1.9-2.1 GPa, 850-950 ${ }^{\circ} \mathrm{C}$. Dashed line of NaCpx is the same as in Fig. 7. Abbreviations are the same as in Fig. 7. b) Isopleths of $\mathrm{X}_{\mathrm{Na}}$-in-feldspar, XFe-in-garnet and $\mathrm{XMg}_{\mathrm{Mg}}$-in-garnet and isomodes of garnet within the $P$ - $T$ space. 
a)
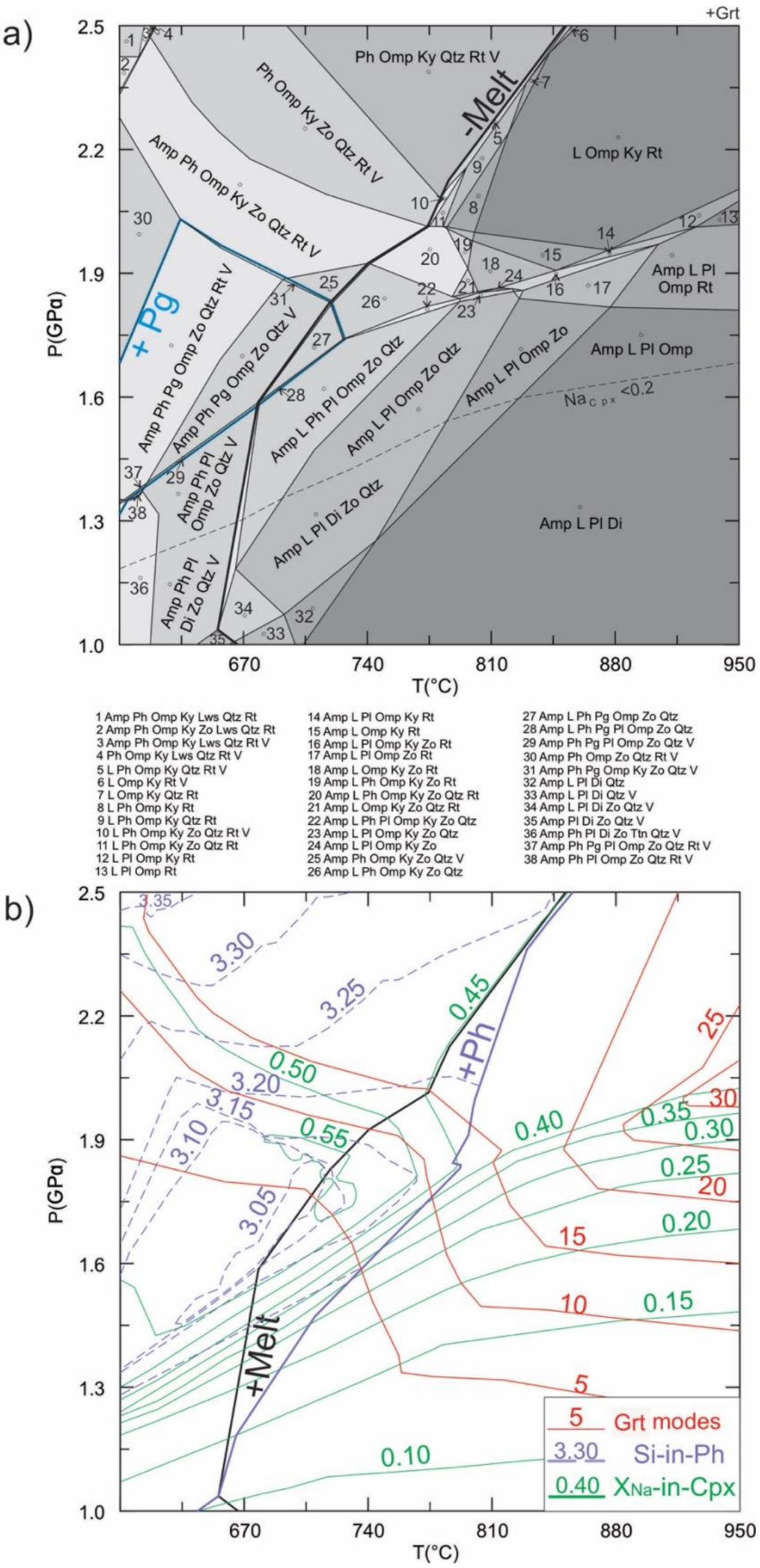
Figure S3. a) Calculated $P-T$ phase diagram for a melt-reintegrated composition of the sample 03-57. See text for detailed modeling parameters. The pseudosection is highlighted for the phase boundaries of paragonite and melt, and is saturated with fluid at subsolidus conditions. Dashed

line of NaCpx and mineral abbreviations are the same as in Fig. 7. b) Isopleths of Si-in-Ph and XNa-in-Cpx and isomodes of garnet on the modeled diagram.

\section{Supplement SII}

Bulk composition of the eclogite 03-59.

The bulk composition was obtained using wavelength dispersive X-ray fluorescence (XRF) spectrometry at Washington State University (Table S1). 
Table S1. XRF-derived bulk rock composition of the zoisite eclogite 03-59. Note: All the measured iron was assumed to be FeO. LOI stands for loss on ignition. - marks unconsidered datasets.

\begin{tabular}{cc} 
& XRF data \\
\hline $\mathrm{Na} 2 \mathrm{O}$ & 2.08 \\
$\mathrm{MgO}$ & 3.32 \\
$\mathrm{Al}_{2} \mathrm{O}_{3}$ & 27.64 \\
$\mathrm{SiO}_{2}$ & 48.17 \\
$\mathrm{~K}_{2} \mathrm{O}$ & 0.14 \\
$\mathrm{CaO}$ & 14.43 \\
$\mathrm{TiO}_{2}$ & 0.122 \\
$\mathrm{MnO}$ & 0.047 \\
$\mathrm{FeO}$ & 3.10 \\
$\mathrm{P} 2 \mathrm{O} 5$ & 0.035 \\
$\mathrm{Total}$ & 99.10 \\
\hline LOI $(\%)$ & 0.48 \\
\hline
\end{tabular}

